\title{
Perbedaan Penggunaan Active Birth dengan Metode Birthball Dan Hypnobirthing terhadap Lama Inpartu Kala I
}

\author{
Ika Yulia Darma*, Meldafia Idaman, Silvi Zaimy, Riri Yulia Handayani \\ STIKES Syedza Saintika \\ Jln. Prof Dr Hamka No 228 Padang \\ *Correspondence email: ika_yd1102@yahoo.com
}

\begin{abstract}
Abstrak. Persalinan adalah suatu proses yang fisiologis. Pada ibu bersalin rentang waktu yang ditandai dengan kontraksi uterus ditandai dengan nyeri, teratur, dilatasi serviks dan penipisan serviks. Salah satu metode penggunaan active birth yang telah dilakukan di Indonesia adalah penggunaan birth ball dan hypnobirthing sebagai bentuk upaya pemberian asuhan sayang ibudalam membantu proses persalinan yang evidance base. Tujuan penelitian ini adalah mempelajari perbedaan penggunaan active birth dengan metode birthball dan hypnobirthing terhadap lama inpartu kala I. Jenis penelitian ini adalah quasy eksperiment dengan pendekatan crossectional, desain penelitian Postest Only Desain. Penelitian dilaksanakan pada bulan Mei - Desember 2020 di Bidan Praktik Mandiri di Kota Padang. Sampel penelitian ini adalah ibu bersalin primipara usia kehamilan yang aterm (37-42 minggu) dan tidak ada memiliki komplikasi. Teknik pengambilan sampel dengan non probability sampling yaitu purposive sampling. Sampel berjumlah 20 orang, dengan 10 sampel menggunakan teknik birthball dan 10 sampel menggunakan teknik hypnobrithing. Data diperoleh dengan menggunakan lembar observasi. Data dianalisis secara univariat dan bivariat. Uji statistik menggunakan uji Mann-Whitney. Hasil penelitian membuktikan bahwa didapatkan rerata lama inpartu kala I dengan menggunakan birthball 3,15 $\pm 0,29$ dan rerata lama inpartu kala I menggunakan hypnobirthing 3,55 $\pm 0,27$. Selisih rerata lama inpartu kala I antara 2 kelompok sebesar 0.40. hasil uji statistik menggunakan uji Mann Whitney didapatkan $p$ value 0,000 ( $p$ $\leq 0,05)$ bearti ada perbedaan yang signifikan penggunaan active birth metode birthball dan hypnoterapi terhadap inpartu kala I. Dapat disimpulkan bahwa perbedaan penggunaan active birth dengan metode birthball dan hypnobirthing terhadap lama inpartu kala I.
\end{abstract}

Kata kunci : Birth Ball; Hypnobirthing; Inpartu Kala I

\begin{abstract}
Childbirth is a physiological process. In women giving birth, the time span is marked by uterine contractions characterized by pain, regularity, cervical dilatation and cervical effacement. One method of using active birth that has been carried out in Indonesia is the use of birth balls and hypnobirthing as a form of effort to provide maternal care in helping the birth process with evidence base The purpose of this study was to study the differences in the use of active birth with birthball and hypnobirthing methods on the length of the first stage of labor. This type of research is a quasi-experimental with a crosssectional approach, the research design is Posttest Only Design. The research was conducted in May - December 2020 at the Independent Practice Midwife in Padang City. The sample of this study were primiparous mothers who had gestational age at term (37-42 weeks) and had no complications. The sampling technique used is non-probability sampling, namely purposive sampling. The sample is 20 people, with 10 samples using the birthball technique and 10 samples using the hypnobirthing technique. Data were obtained by using observation sheets. Data were analyzed by univariate and bivariate. Statistical test using Mann-Whitney test. The results showed that the average length of labor in the first stage using birthball was $3.15 \pm 0.29$ and the average length of labor in the first stage using hypnobirthing was $3.55 \pm 0.27$. The difference in the mean length of the first stage of labor between the 2 groups was 0.40. the results of statistical tests using the Mann Whitney test obtained p value 0.000 (p 0.05 ) which means that there is a significant difference in the use of active birth with the birthball method and hypnotherapy for the first stage of labor. It can be concluded that the difference in the the use of active birth with birthball and hypnobirthing methods on the length of the first stage of labor.
\end{abstract}

Keywords: Birth Ball; Hypnobirthing; the first stage of labor

\section{PENDAHULUAN}

Persalinan adalah suatu proses yang fisiologis. Pada ibu bersalin rentang waktu yang ditandai dengan kontraksi uterus ditandai dengan nyeri, teratur, dilatasi serviks dan penipisan serviks (WHO, 2018).

Pada kala I persalinan terdapat 2 tahap yaitu fase laten dan fase aktif. Pada fase ini, nyeri kontraksi seperti kram berasal dari distensi jaringan rahim dan pelebaran serviks, meluas melalui saraf tulang belakang ke daerah perut dan daerah lumbisakral. Sebagian besar ibu hamil menunjukkan nyeri saat melahirkan sebagai nyeri yang paling dahsyat yang pernah mereka rasakan. Data WHO tahun 2015 mencatata bahwa setiap hari terdapat 830 ribu wanita yang meninggal dunia disebabkan komplikasi kehamilan serta persalinan(WHO, 2015). Angka Kematian Ibu (AKI) pada tahun 2015 masih tinggi yaitu sebesar 305/100.000 kelahiran hidup. Data SDKI 2017 menyebutkan bahwa komplikasi saat persalinan disebabkan oleh partus lama (41\%) (Kemenkes RI, 2017).

Partus lama adalah persalinan yang berlangsung lebih dari 24 jam untuk primipara dan lebih dari 18 jam untuk multipara. Masalah yang terjadi pada persalinan lama adalah fase aktif lebih dari 8 jam, persalinan telah 
berlangsung lebih lama dari 12 jam tetapi bayi belum lahir (Kemenkes RI, 2016).

Salah satu upaya dalam menangani partus lama dapat dilakukan dengan teknik persalinan aktif (active birth). Teknik ini telah diperkenalkan di Ingris sebagai salah satu tindakan dalam membantu kemajuan persalinan. Jalan-jalan, miring ke kiri, miring kekiri, mobilisasi, pendampingan suami, yoga, kompres hangat dingin, bola-bola persalinan (birth ball) dan hypnobrithing merupakan Metode yang yang dapat dilakukan dalam teknik active birth j(Bobak, 2010)(Reeder \& et al, 2017). Adapun manfaat dari teknik ini yaitu mengurangi rasa sakit pada ibu karena kontraksi rahim bergerak kebagian depan rahim, lamanya inpartu kala I, lebih sedikit resiko robekan perineum pada stadium II dan mengurangi terapi medis yang dapat menyebabkan efek samping pada ibu dan bayi (Icesmi, 2013).

Salah satu metode penggunaan active birth yang telah dilakukan di Indonesia adalah penggunaan birth ball dan hypnobirthing sebagai bentuk upaya pemberian asuhan sayang ibu dalam membantu proses persalinan yang evidance base.

Birthball merupakan salah satu metode active birth menggunakan bola pilates yang membantu ibu inpartu kala I. Penggunaan bola pilates dengan berbagai posisi untuk membantu mempercepat lamanya inpartu kala I. Dengan melakukan gerakan seperti duduk dibola dan bergoyang-goyang, sehingga membuat kemajuan persalinan, memberikan rasa nyaman dan, serta meningkatkan sekresi endoprin disebabkan kelenturan dan kelengkungan bola merangsang reseptor dipanggul (Souza, 2016)

Hypnobirthing adalah latihan menanam sugesti untuk pikiran bawah sadar ibu untuk mendukung kesadaran pikirannya dan kendalikan tindakannya dalam menjalani persalinan sehingga membantu ibu menjadi tenang saat menghadapi persalinan (Simkin \& Bolding, 2017).

Penelitian yang dilakukan oleh (Darma \& et al, 2020) (Darma \& Abdillah, 2020) menyatakan bahwa penggunaan birthball dan hypnobirthing memberikan pengaruh yang signifikan terhadap lamanya inpartu kala I persalinan di PMB Kota Padang.

Tujuan penelitian ini adalah mempelajari perbedaan penggunaan active birth dengan metode birthball dan hypnobirthing dalam proses kemajuan persalinan.

\section{METODE}

Jenis penelitian ini adalah quasy eksperiment dengan pendekatan crossectional, desain penelitian Postest Only Desain (Siyoto \& Sodik, 2015). Penelitian dilaksanakan pada bulan Mei - Desember 2020 di Bidan Praktik Mandiri di Kota Padang. Sampel penelitian ini adalah ibu bersalin primipara yang aterm (37-42 minggu) dan tidak ada memiliki komplikasi. Teknik pengambilan sampel dengan non probality sampling yakni purposive sampling. Sampel berjumlah 20 orang, dengan 10 sampel menggunakan teknik birthball dan 10 sampel menggunakan teknik hypnobrithing. Kriteria inklusi dalam penelitian ini ibu hamil inpartu kala I fase aktif dengan pembukaan $6 \mathrm{~cm}$, bagian terendah kepala, tidak ada komplikasi dengan penyulit, dan DJJ normal. Data diperoleh dengan menggunakan lembar observasi. Data dianalisis secara univariat dan bivariat. Uji statistik menggunakan uji Mann-Whitney.

\section{HASIL DAN PEMBAHASAN Analisa Univariat}

Tabel 1. Rerata Penerapan Active Birth Menggunakan Birth Ball dan Hypnobirthing Terhadap Lama Inpartu Kala I

\begin{tabular}{lccc}
\hline \multicolumn{1}{c}{ Perlakuan } & Median & Min-Max & SD \\
\hline Birth ball & $\mathbf{3 , 1 5}$ & $\mathbf{2 , 5 0 - 3 , 3 5}$ & $\mathbf{0 , 2 9}$ \\
Hypnobrithing & $\mathbf{3 , 5 5}$ & $\mathbf{3 , 4 5 - 4 , 1 0}$ & $\mathbf{0 , 2 7}$ \\
\hline
\end{tabular}

Dari tabel 1 diperoleh bahwa rerata lamanya inpatu kali I dengan menggunakan birthball 3,15 $\pm 0,29$ dan rerata kemajuan persalinan menggunakan hypnobirthing 3,55 $\pm 0,27$. Selisih rerata kemajuan perslainan antara 2 kelompok sebesar 0.40 .

\section{Analisa Bivariat}

Tabel 2. Perbedaan Penerapan Activ Birth Menggunakan Birth Ball dan Hypnobirthing Terhadap lama Inpartu Kala I

\begin{tabular}{lcc}
\hline \multicolumn{1}{c}{ Perlakuan } & N & p value \\
\hline Birth ball & 10 & 0,000 \\
Hypnobrithing & 10 & \\
\hline
\end{tabular}

Dari tabel diatas diperoleh hasil uji statistik menggunakan uji Mann Whitney didapatkan $p$ value 0,000 ( $\mathrm{p} \leq 0,05$ ) bearti ada perbedaan yang signifikan penggunaan active birth metode birthball dan hypnoterapi terhadap lamanya Inpartu kala I.

\section{Pembahasan}

Dari hasil diatas didapatkan rerata kemajuan persalinan dengan menggunakan birthball 3,15 $\pm 0,29$ dan rerata lamanya Inpartu Kala I menggunakan hypnobirthing $3,55 \pm 0,27$. Selisih rerata kemajuan perslainan antara 2 kelompok sebesar 0.40 .

Berdasarkan hasil penelitian menunjukan bahwa hasil uji statistik menggunakan uji Mann Whitney didapatkan $p$ value $0,000(\mathrm{p} \leq 0,05)$ bearti ada perbedaan yang signifikan penggunaan active birth metode birthball dan hypnoterapi terhadap lamanya Inpartu Kala I.

Penelitian yang dilakukan Retno Asih dkk (2019) dengan hasil analisis bahwa efektivitas Teknik Pelvic Rocking (Birth Ball) dalam mempercepat persalinan kala 1 menyatakan sangat efektif dalam percepatan persalainan kala 1 dengan waktu 2,18 jam dengan rerata 
percepatan persalinan 1-2 jam dengan standar deviasi 0,883 den $\mathrm{p}$ value $0,045(\mathrm{p}<0,05)$.

Penelitian yang dilakukan Buulolo, Ramadhani (2016) bahwa efektivitas hypnobirthing dengan lama proses persalinan kala I Fase Aktif pada ibu bersalin primipara dengan nilai $\mathrm{p}<0,05$. Rerata lama persalinan primipara pada kelompok ibu yang dilakukan hypnobirthing sebesar 4,13 jam (Buulolo, 2016)

Birth ball yang digunakan pada persalinan dapat menurunkan rasa nyeri. Hal ini disebabkan adanya rangsangan refleks postural, menjaga keadaan postur tulang belakang dalam keadaan baik mengakibatkan mengurangi rasa cemas dan menjaga otot-otot serta, dalam penggunaan pethidin relatif sedikit, membantu penurunan kepala janin, mempercepat lamanya kala 1 serta meningkatkan rasa nyaman dan ketenangan ibu, selain itu juga diperoleh bahwa ibu bersalin merasa lebih nyaman, tenang, santai dan $95 \%$ responden menyatakan bahwa penggunaan birth ball atau bola pilates dapat memberikan kenyamanan(Makvandi \& et al, 2015)

Peneliti lain membuktikan bahwa lama inpartu kala I fase aktif persalinan (pembukaan serviks uteri) $30 \%$ lebih pendek dan tidak terdapat penyulit pada kala II persalinan secara jelas pada kelompok yang melakukan metode ini (Sriwenda, 2016)

Birth Ball digunakan secara pelvic rocking dapat memperkuat otot-otot perut serta pinggang, mengurangi tekanan pada pinggang, mengurangi tekanan pada kandung kemih, membantu ibu lebih santai sehingga dapat memberikan kenyamanan dan ketenangan yang memberikan dampak pada penurunan rasa nyeri pada persalinan yang dirasakan ibu. Pergerakan dengan menggunakan bola pilates dengan pelvic rocking juga memberikan tujuan meningkatkan otot-otot panggul, memberikan peregangan perineum dengan optimal, memperluas aliran oksigen dan sirkulasi darah ke janin dan posisi yang efektif untuk penurunan janin sehingga janin dapat turun dengan mudah dan cepat selama proses persalinan dan rasa nyeri pun berlangsung singkat (Zaky, 2016).

Manfaat dari birth ball selama persalinan adalah mengurani rasa sakit, menurunan tingkat kecemasan, dan meminimalkan penggunaan analgesik, kepala janin lebih mudah turun dan rotasi, durasi yang lebih pendek dari kala 1 persalinan dan meningkatkan rasa nyaman dan ketenangan ibu. Secara psikologis, penggunaan bola pilates dapat meningkatkan postur tubuh, keseimbangan, koordinasi, dan keadaan tubuh karena sifatnya yang dinamis sehingga membantu ibu menjaga kontrol tubuhnya dan membangun kepercayaan diri (Makvandi $\&$ et al, 2015)

Hypnobirthing dikaitkan dengan memperpendek tahap pertama persalinan, terutama pada ibu primipara dan mungkin mengurangi penggunaan analgesik. Buruh dapat dilewati tanpa komplikasi dan tidak memerlukan pembedahan, forsep atau vakum dan bahkan bayi yang lahir normal nilai APGAR. Hypnobirthing adalah metode yang mengajarkan ibu untuk memahami dan melepaskan ketegangan ketakutan, rasa sakit sindrom (sindrom ketakutan, ketegangan dan rasa sakit) yang menyebabkan rasa sakit dan ketidaknyamanan selama persalinan (Mahmudah, 2013)

Metode hypnobirthing adalah kombinasi proses kelahiran alami dengan hipnotis untuk membangun persepsi positif dan kepercayaan diri dan mengurangi ketakutan, kecemasan dan ketegangan, dan panik sebelum, selama dan setelah melahirkan (Gupta \& Nikdem, 2013)

Metode hypnobirthing didasarkan pada keyakinan bahwa setiap ibu yang melahirkan memiliki potensi untuk menjalani proses kelahiran secara alami, tenang, dan nyaman (tanpa rasa sakit). Metode ini digunakan untuk kendalikan pikiran ibu dan masukkan sugesti positif dalam benak ibu, sehingga dapat memberikan rasa relaksasi pada ibu, peningkatan rasa ibu kesejahteraan dapat mendorong proses fisiologis pada saat persalinan (Gallo \& et al, 2018)

Pada penelitian ini, terdapat perbedaan penggunaan birth ball dan Hypnobirthing dalam kemajuan persalinan kala 1 fase aktif. Didapatkan hasil lebih cepat kemajuan persalinan kala 1 pada primipara dengan penggunaan Birth Ball dibandingkan hypnobirthing. Birthball membantu mempercepat lamanya inpartu kala I. Dengan melakukan gerakan seperti duduk dibola dan bergoyang-goyang, akan menggerakan paha, memutar. Hal ini akan mendorong kepala bayi menekan serviks dan membantu mempercepat inpartu pada kala I.

\section{KESIMPULAN}

Ada perbedaan penggunaan activ birth dengan metode birthball dan hypnobirthing terhadap lama inpartu kala I.

\section{DAFTAR PUSTAKA}

Bobak. (2010). Textbook of Maternity Nursing. Jakarta: EGC.

Buulolo, D. . (2016). The effect of hypnobirthing techniques on the duration of the process stage I labor in the active phase and pain levels in labor at Eka SriWahyuni Clinic, Medan Denai District. USU.

Darma, I. Y., \& Abdillah, N. (2020). Penerapan Teknik Active Birth Menggunakan Birth Ball Terhadap Kemajuan Persalinan Kala I Pada Ibu Bersalin. Jurnal Ilmu Kesehatan (JIK), 4(2).

Darma, I. Y., \& et al. (2020). The effect of the implementation active birth technique using hypnobirthing accelerated the progress of the first stage of labor among intrapartum mother. International Journal of Community Medicine And Public Health, 7(12), 4745. https://doi.org/10.18203/2394- 
Ika Yulia Darma, Meldafia Idaman, Silvi Zaimy dan Riri Yulia Handayani, Perbedaan Penggunaan Active Birth dengan Metode Birthball Dan Hypnobirthing terhadap Lama Inpartu Kala I

6040.ijcmph20205144

Gallo, R., \& et al. (2018). Sequential Application Of Non-Pharmacological Interventions Reduces The Severity Of Labour Pain, Delays Use Of Pharmacological Analgesia, And Improves Some Obstetric Outcomes: A Randomised Trial. Journal Physiotherapy, 64(1), 33-40.

Gupta, J., \& Nikdem, V. (2013). Position for women during second stage of labor. Care practices that promote normal Birth 5: Non-supine (e.g., upright or side lying) positions for birth. Lamaze Institute.

Icesmi, M. (2013). Kehamilan, Persalinan dan Post Partum. Bandung: Nuha Medika.

Kemenkes RI. Profil Kesehatan Indonesia 2016. , (2016).

Kemenkes RI. Survei Demografi dan Kesehatan Indonesia (SDKI). , (2017).

Mahmudah, S. (2013). Pengaruh Pemberian Hypnobirthing Dengan Lama Kala I Fase Aktif Pada Ibu Berslain di BPS Prita Yusnita Mangunsari Salatiga. Stikes Ngudi Waluyo.

Makvandi, S., \& et al. (2015). Effect Of The Birth Ball On Labor Pain Relief: A Systematic Review and Meta- Analysis. Journal of Obstetrics and Gynaecology Research, 41(11), 1679-1686.

Reeder, S. ., \& et al. (2017). Maternity Nursing: family, newborn, and women's health care (18th ed.). Philadelphia: Lippincott.

Simkin, P., \& Bolding, A. (2017). Update on nonpharmacologic capproachestorelieve Labor Pain and Prevent Suffering. Journal of Midwifery \& Women's Health, 49(6).

Siyoto, \& Sodik. (2015). Dasar Metodologi Penelitian. Yogjakarta: Literasi Media Publishing.

Souza, J. . (2016). Maternal Position During the First Stage of Labor: a systematic riview. Reproductive Health, 3(10).

Sriwenda, D. (2016). Efektivitas Latihan Birthball Terhadap Efikasi Diri Primipara Dengan Persalinan Normal. Indonesian Journal of Nursing \& Midwifery, 4(3), 141-147.

WHO. Global Health Observatory (GHO) Data: Maternal Mortality., (2015).

WHO. (2018). Intrapartum care for a positive childbirth experience.

Zaky, N. . (2016). Effect of Pelvic Rocking Exercise Using Sitting Position On The Birth Ball During The First Stage Of Labor On Its Progress. IOSR Journal of Nursing., 5(4), 19-27. 